\title{
A Study on Family Support and Resilience of the Elderly
}

\author{
Sungsim Lee ${ }^{1}$ and Youngsoon Choi ${ }^{2 *}$ \\ ${ }^{1}$ Department of Nursing, Gangneung Yeongdong College, 357, \\ Gongje-ro, Gangneung-si, Gangwon-do, Republic of Korea \\ $2^{2}$ Department of Nursing, Kangwon National University, Samcheck-si, Gangwon-do, \\ 25949, Republic of Korea \\ ${ }^{1}$ kkamansung@naver.com, ${ }^{2 *}$ ysc615@hanmail.net
}

\begin{abstract}
This study attempted to provide basic data on mental health by identifying the factors that influence the elderly's personal characteristics on family support and resilience. Data collection conducted from October 1, 2019 to January 31, 2020 with the consent of the subjects, and 170 participants used for the final analysis. The questionnaire was composed of demographic characteristics, family support, and resilience. The collected data were analyzed using descriptive statistics, t-test, ANOVA, Pearson's correlation, and multiple regression using the SPSS 21.0 statistical program. As result of this study, there were statistically significant differences in family support according to general characteristics in terms of education level, religion, living standard, housing type, subjective health status, and health concern. Resilience showed statistically significant differences in education level, religion, occupation, monthly income, living standard, subjective health status, and health interest. Family support had a positive correlation with resilience, and resilience had a positive correlation with subjective health status. In the results of regression analysis, monthly income, standard of living, and family support were the predictors of resilience as factors affecting resilience, and the total explanatory power of these variables was $36.5 \%$. This study expected to be able to be used as a basis for improving the mental health of the elderly.
\end{abstract}

Keywords: Elderly, Family support, Resilience, Subjective health status

\section{Introduction}

In modern society, the general standard of living has improved due to the development of science, improvement of national income through economic growth, and improvement of living conditions. In addition, the average life expectancy of the elderly is prolonging as the health condition improves due to the development of medicine and health and hygiene [1].

The term 'old man' means that it declines biologically, physically, mentally, socially, and spiritually as he ages, and is defined in various ways depending on social and cultural situations and aging phenomena showing individual differences [2].

The International Association of Geriatrics stipulates that the elderly is a person with complex physiological, psychological, environmental and behavioral changes occurring in human aging, and said that it refers to a person with the following five characteristics. In other words, those who have a deficiency in their own organization capable of adapting to environmental changes, those who are in a period of declining their integration ability, those

Article history:

Received (December 28, 2020), Review Result (January 29, 2021), Accepted (March 4, 2021) 
who are in a period of decay in human organs and organizational functions, and those who are in a period of decline in the function of the human body, mentally adaptation of life itself. It is a person who is becoming deficient, a person at a time when adaptation is declining due to exhaustion of the human body's tissue reserve capacity. As such, it can be defined that the elderly are people whose physiological, psychological, and social functions are weakened during the aging process and thus their independent living ability and environmental adaptation ability are declining [2].

Family support is a life-long social support system composed of family members, and refers to the function of support that enables family members to love, respect, and have a sense of value through interactions [3], In addition, family support is not only a favorable feeling for others, recognition of others' words and actions, and support of symbolic and material help by others, but also anxiety, depression, and frustration, which are the main factors that cause family members to fail to adapt in stress or crisis situations. It refers to an important, direct and primary social support system that functions to reduce the same negative emotions [4].

Seo Yeon-hee's study showed that the higher the family support, the higher the mental health, and the higher the family support, the higher the quality of life [5]. In other words, families interact, have the ability to support and protect their family members individually and collectively, and have importance as a lifelong social support system to adapt to crises. Therefore, the family can be seen as a meaningful role to help buffer psychological and social adaptation of ego identity crisis and life events variables [6].

Resilience is in the dictionary meaning "a property or ability to overcome a failure or negative situation and restore the original stable psychological state", or as a "positive force to overcome adversity or hardship" in psychology. Because resilience measured by different factors, concepts can be variously defined for each field. Psychologically, it used as a human ability to overcome the trials, trouble, and difficulties of life and to leap successfully in such an environment. [2].

Eun-suk Hong refers to resilience as 'spiritual resistance', and when he judges that all human beings have the power to positively resist various difficulties and trials that arise, resilience is thought to have an important influence in the elderly [7], In a study by Park Jeong-suk et al., it was found that the higher the resilience of the elderly, the less suicidal thoughts [8].

Therefore, this study is to confirm the factors that influence family support and resilience according to the general characteristics of the elderly. This study conducted to provide basic data for developing mental health education materials and nursing intervention programs to improve the quality of life of the elderly by identifying detailed factors that affect the elderly's resilience.

\section{Research method}

\subsection{Research design}

This study is a descriptive research study using a structured questionnaire to understand the influence of the elderly on family support and resilience.

\subsection{Research Subject}

The subjects of this study were the elderly in P city located in Gyeonggi-do, an urban and rural complex city. Convenience extracted as a person who understood the purpose of the study and voluntarily agreed to participate in the study in writing. As for the number of samples, the number required for multiple regression analysis was calculated using the G*Power 3.1.5 
program. When the significance level was .05 , the power was .95 , and the effect size was set to an intermediate level of .15, the calculated sample size was 138. In anticipation of the dropouts, 180 copies were distributed, and 175 copies were recovered, but 170 data were used for the final analysis, excluding 5 copies with insufficient responses.

\subsection{Research tool}

\subsubsection{Family support}

In this study, in order to measure the family support of the elderly, Kang Hyun-suk [9] used a family support measurement tool that modified and supplemented the tool of Cobb [10] according to the situation in Korea. It is a total of 11 questions, and the higher the score, the higher the level of family support. Negative questions were calculated by inversely converting the score, and consisted of a 5-point scale, and the score was always yes (5 points), often yes (4 points), average ( 3 points), usually not ( 2 points), at all It is not ( 1 point). The higher the score, the higher the level of family support perceived by the elderly. The reliability (Cronbach $\alpha$ ) in Kang Hyeon-suk's study was .91, and the reliability in this study was Cronbach's $\alpha=.987$.

\subsubsection{Resilience}

Baek developed the Connor-Davidson Resilience Scale (CD-RISC) developed by Connor and Davidson [11] for the elderly's resilience scale, and this Korean Connor-Davidson resilience tool (K-CD-RISC) was used [12]. The sub-area consists of 22 questions including 8 toughness questions, 7 persistence questions, 4 optimism questions, 2 support questions, and 1 spirituality question. It consisted of a 5-point Likert scale, and the score was always yes (5 points), often yes (4 points), average ( 3 points), usually not ( 2 points), at all It is not (1 point). The score range measured from the lowest 22 points to the highest 110 points. In the study of Connor and Davidson at the time of development, Cronbach' s $\alpha$ was .89, in Baek's study Cronbach's $\alpha$ was .93, and in this study, Cronbach's $\alpha$ value was .978, which showed adequate reliability.

\subsection{Data collection procedure}

The data collection period of this study was from October 1, 2019 to January 31, 2020, before collecting the data, the purpose of the study, the data collection, and the method of discarding the data at the end of the study were explained, and then the questionnaire was conducted after receiving the written consent from the person who wanted to participate. Explain that the questionnaire can be discontinued when withdrawing from the study during the questionnaire preparation and guided that there is no disadvantage. The average time spent in the questionnaire was 10-15 minutes. Total 180 questionnaires were distributed and 175 copies were collected, and 170 copies were used for the final analysis, excluding 5 copies of which responses were unfaithful.

\subsection{Data analysis method}

The collected data analyzed using the SPSS 21.0 program, the difference and level of family support and resilience according to demographic and sociological characteristics analyzed by descriptive statistics, t-test, and ANOVA, and the Scheff'e test was used for post-mortem test. The correlation between family support and resilience analyzed by Pearson's correlation, and the effect on resilience was analyzed by Multiple regression. 


\section{Research result}

\subsection{Differences in family support and resilience according to the characteristics of the subject}

Looking at the difference between family support and resilience according to the general characteristics of the subject, family support is the level of education $(\mathrm{F}=3.95 \mathrm{p}<.05)$, religion $(\mathrm{F}=3.01, \mathrm{p}<.05)$, standard of living $(\mathrm{F}=2.95), \mathrm{p}<.05)$, housing type $(\mathrm{F}=4.58, \mathrm{p}<.05)$, subjective health $(\mathrm{F}=8.10, \mathrm{p}<.001)$, health concerns $(\mathrm{F}=9.35, \mathrm{p}<.001)$ showed a statistically significant difference.

Resilience is the degree of education $(F=3.63, p<) .05)$, religion $(F=2.67), p<.05)$, occupation $(\mathrm{F}=-1.72, \mathrm{p}<.05)$, monthly income $(\mathrm{F}=10.21, \mathrm{p}<.001)$, standard of living $(\mathrm{F}=12.75, \mathrm{p}<.001)$, subjective health $(\mathrm{F}=4.21, \mathrm{p}<.05)$ health concerns $(\mathrm{F}=3.04 \mathrm{p}<.05)$ showed statistically significant differences [Table 1].

Table 1. Difference in family support, resilience of according to general characteristics $\quad \mathrm{N}=170$ )

\begin{tabular}{|c|c|c|c|c|c|c|c|}
\hline \multirow[b]{2}{*}{ characteristics } & \multirow{2}{*}{\multicolumn{2}{|c|}{ categories }} & \multirow[b]{2}{*}{$\mathrm{n}(\%)$} & \multicolumn{2}{|c|}{ family support } & \multicolumn{2}{|c|}{ resilience } \\
\hline & & & & $\mathrm{M} \pm \mathrm{SD}$ & $\begin{array}{c}\mathrm{t} / \mathrm{F}(p), \\
\text { Scheffe }\end{array}$ & $\mathrm{M} \pm \mathrm{SD}$ & $\begin{array}{l}\mathrm{t} / \mathrm{F}(p) \\
\text { Scheffe }\end{array}$ \\
\hline \multirow{2}{*}{ gender } & male & & $52(30.6)$ & $40.57 \pm 12.07$ & \multirow{2}{*}{$-.999(.657)$} & $79.50 \pm 13.68$ & \multirow{2}{*}{$.136(.687)$} \\
\hline & female & & $118(69.4)$ & $42.57 \pm 12.25$ & & $79.19 \pm 13.43$ & \\
\hline \multirow{3}{*}{ age(year) } & 65-69year & & $27(15.9)$ & $38.44 \pm 14.09$ & \multirow{3}{*}{$.919(.401)$} & $77.15 \pm 13.80$ & \multirow{3}{*}{$.47(.630)$} \\
\hline & 70-79year & & $97(57.1)$ & $42.02 \pm 11.84$ & & $79.42 \pm 13.78$ & \\
\hline & $<80$ year & & $46(27.0)$ & $41.13 \pm 11.49$ & & $80.26 \pm 12.73$ & \\
\hline \multirow{4}{*}{ education } & no learning & $\mathrm{a}$ & $30(17.7)$ & $39.26 \pm 13.87$ & \multirow{4}{*}{$\begin{array}{c}3.90(<.05)^{*} \\
\mathrm{~b}>\mathrm{c}>\mathrm{d}, \mathrm{a}\end{array}$} & $73.77 \pm 15.70$ & \multirow{4}{*}{$\begin{array}{c}3.63(<.05)^{*} \\
\mathrm{c}>\mathrm{b}>\mathrm{d}, \mathrm{a}\end{array}$} \\
\hline & $\begin{array}{c}\text { elementary } \\
\text { school graduate }\end{array}$ & $\mathrm{b}$ & $71(41.8)$ & $44.50 \pm 10.70$ & & $81.55 \pm 11.67$ & \\
\hline & $\begin{array}{l}\text { middle school } \\
\text { graduate }\end{array}$ & $\mathrm{c}$ & $35(20.5)$ & $40.74 \pm 11.64$ & & $82.29 \pm 10.82$ & \\
\hline & $\begin{array}{l}\text { high school } \\
\text { graduate }\end{array}$ & d & $34(20.0)$ & $36.52 \pm 12.31$ & & $76.35 \pm 15.67$ & \\
\hline \multirow{4}{*}{ religion } & no religion & $\mathrm{a}$ & $52(30.5)$ & $38.05 \pm 12.42$ & \multirow{4}{*}{$\begin{array}{c}3.01(<.05)^{*} \\
\mathrm{~d}>\mathrm{c}>\mathrm{b}>\mathrm{a}\end{array}$} & $76.81 \pm 14.70$ & \multirow{4}{*}{$\begin{array}{c}2.67(<.05)^{*} \\
\mathrm{~d}>\mathrm{c}>\mathrm{b}>\mathrm{a}\end{array}$} \\
\hline & Christian & $\mathrm{b}$ & $63(37.0)$ & $40.68 \pm 12.13$ & & $77.78 \pm 14.22$ & \\
\hline & Catholic & $\mathrm{c}$ & $30(17.7)$ & $45.60 \pm 10.82$ & & $82.63 \pm 11.30$ & \\
\hline & Buddhism & d & $25(14.8)$ & $43.84 \pm 12.12$ & & $84.24 \pm 9.07$ & \\
\hline \multirow{4}{*}{ marriage } & single & a & $10(6.9)$ & $44.60 \pm 10.73$ & \multirow{4}{*}{$1.93(.126)$} & $77.90 \pm 9.85$ & \multirow{4}{*}{$.38(.771)$} \\
\hline & have spouse & $\mathrm{b}$ & $80(47.2)$ & $42.20 \pm 11.07$ & & $79.22 \pm 9.21$ & \\
\hline & bereavement & $\mathrm{c}$ & $65(38.9)$ & $40.83 \pm 12.23$ & & $79.22 \pm 12.70$ & \\
\hline & divorce & d & $10(5.9)$ & $34.29 \pm 16.97$ & & $76.00 \pm 11.80$ & \\
\hline \multirow{4}{*}{ family form } & alone & $\mathrm{a}$ & $77(45.3)$ & $40.84 \pm 13.37$ & \multirow{4}{*}{$.93(.425)$} & $79.43 \pm 13.46$ & \multirow{4}{*}{$.16(.927)$} \\
\hline & couple & $\mathrm{b}$ & $48(28.2)$ & $40.75 \pm 10.57$ & & $78.42 \pm 14.39$ & \\
\hline & children & $\mathrm{c}$ & $43(25.3)$ & $41.74 \pm 11.54$ & & $79.81 \pm 12.94$ & \\
\hline & Other & d & $2(1.2)$ & $55.00 \pm .00$ & & $83.50 \pm 6.36$ & \\
\hline occupation & no & & $116(68.2)$ & $47.33 \pm 11.54$ & $-1.48(.078)$ & $78.09 \pm 14.23$ & $-1.72(<.05)^{*}$ \\
\hline
\end{tabular}




\begin{tabular}{|c|c|c|c|c|c|c|c|}
\hline & yes & & $54(31.8)$ & $50.07 \pm 10.85$ & & $81.87 \pm 11.35$ & \\
\hline \multirow{5}{*}{$\begin{array}{l}\text { monthly } \\
\text { income }\end{array}$} & $>500,000$ won & a & $51(30.0)$ & $40.62 \pm 14.51$ & \multirow{4}{*}{$1.02(.394)$} & $73.55 \pm 13.93$ & \multirow{4}{*}{$\begin{array}{c}10.21(<.001)^{* *} \\
\mathrm{e}, \mathrm{c}, \mathrm{d}>\mathrm{a}, \mathrm{b}\end{array}$} \\
\hline & $\begin{array}{c}500,000 \\
-1,000,000 \text { won }\end{array}$ & $\mathrm{b}$ & $29(17.1)$ & $40.06 \pm 12.01$ & & $72.10 \pm 17.03$ & \\
\hline & $\begin{array}{c}1,000,000 \\
-1,500,000 \text { won }\end{array}$ & $\mathrm{c}$ & $76(44.6)$ & $46.45 \pm 11.91$ & & $85.12 \pm 8.65$ & \\
\hline & $<1,500,000$ won & d & $11(6.5)$ & $49.00 \pm 10.39$ & & $82.18 \pm .00$ & \\
\hline & other & $\mathrm{e}$ & $3(1.8)$ & $55.00 \pm .00$ & & $88.00 \pm .00$ & \\
\hline \multirow{4}{*}{$\begin{array}{l}\text { standard of } \\
\text { living }\end{array}$} & very difficult & a & $8(4.7)$ & $29.75 \pm 14.73$ & \multirow{4}{*}{$\begin{array}{c}2.95(<.05)^{*} \\
\mathrm{~d}>\mathrm{c}, \mathrm{b}>\mathrm{a}\end{array}$} & $62.50 \pm 17.11$ & \multirow{4}{*}{$\begin{array}{c}12.75(<.001)^{*} \\
\mathrm{~d}, \mathrm{c}>\mathrm{b}>\mathrm{a}\end{array}$} \\
\hline & difficult & $\mathrm{b}$ & $44(25.9)$ & $40.22 \pm 13.06$ & & $72.70 \pm 15.28$ & \\
\hline & average & $\mathrm{c}$ & $111(65.3)$ & $42.27 \pm 11.30$ & & $82.71 \pm 10.70$ & \\
\hline & can afford & d & $7(4.1)$ & $43.71 \pm 10.65$ & & $85.57 \pm 5.99$ & \\
\hline \multirow{3}{*}{ housing type } & self & a & 101(59.4) & $42.58 \pm 10.24$ & \multirow{3}{*}{$\begin{array}{c}4.58(<.05)^{*} \\
\quad \mathrm{c}>\mathrm{a}>\mathrm{b}\end{array}$} & $79.82 \pm 12.45$ & \multirow{3}{*}{$1.03(.361)$} \\
\hline & charter & $\mathrm{b}$ & $42(24.7)$ & $36.42 \pm 13.72$ & & $78.83 \pm 15.53$ & \\
\hline & monthly & $\mathrm{c}$ & $27(15.9)$ & $42.51 \pm 14.32$ & & $81.11 \pm 13.71$ & \\
\hline \multirow{4}{*}{$\begin{array}{l}\text { subjective } \\
\text { health status }\end{array}$} & not very healthy & a & $14(8.2)$ & $28.50 \pm 10.50$ & \multirow{4}{*}{$\begin{array}{c}8.10(<.001)^{* *} \\
\text { b,d,c>a }\end{array}$} & $68.50 \pm 18.22$ & \multirow{4}{*}{$\begin{array}{c}4.21(<.05)^{*} \\
\mathrm{c}, \mathrm{b}, \mathrm{d}>\mathrm{a}\end{array}$} \\
\hline & not healthy & $\mathrm{b}$ & $68(40.0)$ & $44.60 \pm 11.74$ & & $79.88 \pm 13.08$ & \\
\hline & average & $\mathrm{c}$ & $77(45.3)$ & $40.10 \pm 10.88$ & & $80.52 \pm 12.33$ & \\
\hline & healthy & d & $11(6.5)$ & $43.45 \pm 14.15$ & & $82.00 \pm 10.71$ & \\
\hline \multirow{4}{*}{ health concern } & no concern & a & $2(1.2)$ & $48.00 \pm 9.90$ & \multirow{4}{*}{$\begin{array}{c}9.35(<.001)^{* *} \\
b>a>c>d\end{array}$} & $83.00 \pm 7.07$ & \multirow{4}{*}{$\begin{array}{c}3.04(<.05)^{*} \\
b>a>c>d\end{array}$} \\
\hline & average & $\mathrm{b}$ & $15(8.8)$ & $50.00 \pm 8.64$ & & $83.40 \pm 6.97$ & \\
\hline & concern & $\mathrm{c}$ & $129(75.9)$ & $41.89 \pm 11.79$ & & $80.09 \pm 12.95$ & \\
\hline & very concern & d & $24(14.1)$ & $31.45 \pm 10.28$ & & $72.13 \pm 17.27$ & \\
\hline \multirow[b]{2}{*}{ hospitalization } & no & & $136(80.0)$ & $40.54 \pm 12.37$ & \multirow[b]{2}{*}{$-1.44(.273)$} & $79.05 \pm 13.57$ & \multirow[b]{2}{*}{$-.46(.554)$} \\
\hline & yes & & $34(20.0)$ & $43.88 \pm 10.83$ & & $80.24 \pm 13.19$ & \\
\hline
\end{tabular}

\subsection{The level of family support and resilience of the subject}

The subject's family support was $41.25 \pm 11.285$ points, and the 100 -points conversion score was 74.90 points. The resilience was $79.29 \pm .13 .466$ points, and the 100-points conversion score was 72.08 points. Subjective health status was $2.50 \pm 9.740$ points and 100 points conversion score were 50.00 points [Table 2].

Table 2. Level of family support and resilience $\mathrm{N}=170$ )

\begin{tabular}{|c|c|c|c|}
\hline variable & range & $\mathrm{M} \pm \mathrm{SD}$ & 100 converted points \\
\hline family support & $11 \sim 55$ & $41.21 \pm 11.285$ & 74.90 \\
\hline resilience & $22 \sim 110$ & $79.29 \pm 13.466$ & 72.08 \\
\hline
\end{tabular}




\begin{tabular}{|l|c|c|c|}
\hline subjective health status & $1 \sim 5$ & $2.50 \pm 9.740$ & 50.00 \\
\hline
\end{tabular}

\section{Discussion}

The degree of family support was high at $41.21 \pm 11.285$ points, which is similar to a study measured using the same tool in stroke patients [13]. There was a significant difference in the level of education in family support, and the support of the family was higher for elementary school or middle school graduates than for unschooled or high school graduates. In addition, there was a significant difference in family support to religion, and it found that the case of having a religion was higher than that of not having a religion. The family support showed a significant difference with the standard of living, and it found that family support was higher in the case where there was room in the living standard than in the case where the living standard was difficult. This is similar to the result of a study that showed high family support according to average income [13]. The family support showed a significant difference in the type of housing, and the monthly rent showed higher support for the family than for selfsupport. The family support showed a significant difference in the subjective health status, and the family support was found to be higher in the case of good health status perceived by the person than the case of poor health status. The family support showed a significant difference in health concern, and the case with no health interest showed higher family support than the case with health interest.

The average score for resilience was $79.29 \pm 13.47$ points (100 points conversion score: 72.08 points), and the results were similar to those of the study in stroke patients [13]. There was a significant difference in resilience with the level of education, and elementary or middle school graduates had higher resilience than unschooled or high school graduates. In addition, there was a significant difference in resilience to religion, and it found that those with religion had higher resilience than those without religion. The resilience was significantly different from that of the job, and the resilience was higher than that of no job. The resilience showed a significant difference with monthly income, and the case of high monthly income found to have high resilience. The resilience showed a significant difference in the standard of living, and the high standard of living showed high resilience. The resilience showed a significant difference in the subjective health status, and the resilience found to be high when the self-perceived health status was good. Resilience showed a significant difference in health concern, and those without health concern showed high resilience.

\section{Conclusion}

This study conducted to identify the factors affecting the elderly's family support and resilience, and to provide them as basic data for developing educational materials and nursing intervention programs to improve the elderly's mental health.

Based on the study results to the following suggestions such.

First, there is a need for continuous research and attention on the factors that affect the elderly's family support and resilience.

Second, there is a need for a follow-up study on the relationship between family support and resilience of the elderly and continuous research on resilience.

Third, research and interest in the development and application of intervention programs to improve the resilience of the elderly needed. 


\section{References}

[1] S. L. Kim, "Differences in mental health according to religion and religious activities of the elderly: Focusing on hope, gratitude, death anxiety, and depression," Hanseo University Master's Thesis, (2013)

[2] I. D. Han, C. D. Koo, "Effect of forest healing program on the resilience of elderly people in urban forest," Journal of People, Plants, and Environment, vol.21, no.4, pp.293-303, (2018)

[3] Shanas. E. P., "The family as a social support system in old age," The Gerontologist, vol.19, no.2, pp.169-174, (1979)

[4] S. H. Jang, "A study on the relationship between family support perceived by inpatients and state anxiety," Chosun University Master's Thesis, (1991)

[5] Y. H. Seo, "The effect of cohabitation and family support on mental health and quality of life of the elderly," Dongeui University Master's Thesis, (2011)

[6] Y. E. Kwon, "A study of the relationship between perceived social support and quality of life on cancer patients," Yonsei University Master's thesis, (1990)

[7] E. S. Hong, "Conceptual understanding of resilience and instructional suggestion," Korean Journal of Special Education, vol.41, no.2, pp.45-67, (2006)

[8] J. S. Park, Y. K. Park, S. H. Jeong, C. S. Lee, H. Kim, "Influence of resilience and depression on suicidal education in elderly," Journal of the Korea Gerontological Society, vol.34, no.2, pp.247-258, (2014)

[9] H. S. Kang, "An experimental study of the effects of reinforcement education for rehabilitation on hemiplegia patients' self-care activities," Yonsei University, Master's Thesis, (1984)

[10] Cobb, S., "Social support as a moderate of life stress," Psychosom. Med., vol.38, no.5, pp.300-314, (1976)

[11] Connor, K. M., Davidson, J. R. T., "Development of a new resilience scale: The Connor-Davidson resilience scale (CD-RISC)," Depression and Anxiety, vol.18, no.2, pp.76-82, (2003)

[12] Baek, H., "Reliability and validity of the Korean version of the Connor-Davidson Resilience Scale (K-CDRISC). Eulji University Master's Thesis, (2010)

[13] E. K. Lee, "Impact of disease-related knowledge and family support on resilience in elderly patients with stroke rehabilitation," Eun, Hanyang University Master's Thesis, (2020) 
A Study on Family Support and Resilience of the Elderly

This page is empty by intention. 